\title{
Crescimento e produção de fitomassa de variedades de milho em diferentes manejos da capoeira
}

\author{
Anna Christina Monteiro Roffé Borges(1), Osvaldo Ryohei Kato(1), Hugo Alves Pinheiro(2), \\ Maurício Kadooka Shimizu(1), Lívia Gabrig Turbay Rangel-Vasconcelos ${ }^{(1)}$ \\ e Moisés Cordeiro Mourão de Oliveira Júnior ${ }^{(1)}$
}

${ }^{(1) E m b r a p a ~ A m a z o ̂ n i a ~ O r i e n t a l, ~ T r a v e s s a ~ D r . ~ E n e ́ a s ~ P i n h e i r o, ~ s / n o, ~ C a i x a ~ P o s t a l ~ 48, ~ C E P ~ 66095-100 ~ B e l e ́ m, ~ P A . ~ E-m a i l: ~ a r o f f e @ c p a t u . e m b r a p a . b r, ~}$
okato@cpatu.embrapa.br, mauricio@cpatu.embrapa.br, Igabrig@terra.com.br, mmourao@cpatu.embrapa.br (2)Universidade Federal Rural
da Amazônia, Avenida Presidente Tancredo Neves, no 2.501, Caixa Postal 917, CEP 66077-530 Belém, PA. E-mail: hugo.pinheiro@ufra.edu.br

Resumo - O objetivo deste trabalho foi avaliar o crescimento e a produção de fitomassa de três variedades de milho submetidas a diferentes manejos da capoeira, em sistema de corte e trituração, em Marapanim, nordeste do Pará, no período da seca. Utilizou-se o delineamento experimental de blocos ao acaso, com 18 tratamentos e quatro repetições. As parcelas foram constituídas por três manejos da capoeira: natural, enriquecida com ingá (Inga edulis) e tachi-branco (Sclerolobium paniculatum) e enriquecida com ingá e tachi-branco com adubação fosfatada. Foram introduzidas três variedades de milho (BRS Sol da Manhã, BRS 4154 Saracura e BR 106), distribuídas em subparcelas com ou sem adubação complementar (NPK). Foram avaliadas as variáveis: altura da planta, diâmetro do caule, número de folhas, massa de matéria úmida e seca e estande. Os manejos com capoeira enriquecida e capoeira enriquecida com adubação fosfatada influenciaram positivamente a altura das plantas, o diâmetro do colmo e a produção de fitomassa; a adubação complementar potencializou o efeito dos manejos para estas variáveis.

Termos para indexação: Zea mays, Amazônia, corte e trituração, enriquecimento de capoeira, plantio direto na capoeira.

\section{Growth and phytomass production of maize varieties in different fallow management}

\begin{abstract}
The objective of this work was to evaluate the growth and phytomass production of three maize varieties under different fallow management in a slash and mulch system, in Marapanim, northeast of Pará state, Brazil, during the dry season. The experimental design was a randomized blocks, with 18 treatments and four replicates. The plots consisted of three fallow management: natural, enriched with inga (Inga edulis) and tachi-branco (Sclerolobium paniculatum), and enriched with inga and tachi-branco with phosphorus fertilization. Three maize varieties (BRS Sol da Manhã, BRS 4154 Saracura and BR 106) were introduced and distributed in split-plots with or without additional fertilization (NPK). The variables evaluated were plant height, stem diameter, leaf number, mass of moist and dry matter, and stand. The fallow management with enriched fallow and enriched fallow with phosphorus positively influenced plant height, stem diameter, and moist and dry mass production; the additional fertilization potentialized the effect of fallow management on these variables.
\end{abstract}

Index terms: Zea mays, Amazon, slash and mulch, fallow enrichment, no-tillage in fallow.

\section{Introdução}

Na região amazônica, o sistema de uso da terra é caracterizado pela prática da agricultura rotacional, que intercala períodos de cultivo com curtos períodos de pousio. O preparo da área é realizado, predominantemente, com a prática de derrubada e queima da vegetação. Esta prática apresenta a vantagem de fornecer às culturas, em curto prazo, os nutrientes necessários para seu desenvolvimento. Contudo, sua adoção em sucessivos anos de cultivo leva ao esgotamento do solo, o que faz com que o produtor abandone a área e busque novas áreas para o cultivo, e confere o caráter itinerante da agricultura na Amazônia (Denich et al., 2005; Watrin et al., 2009).

Uma consequência da prática da derrubada e queima é o aumento do desmatamento de áreas de floresta nativa, abandonadas após o cultivo e com baixo potencial de regeneração natural, o que origina áreas de vegetação secundária (capoeira). Essa prática tem sido questionada pelos seus efeitos negativos nas propriedades físicas, químicas e biológicas do 
solo, pelo aumento das emissões de gases nocivos à atmosfera e pelos riscos de incêndios incontroláveis (Denich et al., 2005). Portanto, é fundamental o desenvolvimento de tecnologias que permitam utilizar os recursos naturais com o menor impacto possível ao meio ambiente, recuperar as áreas impactadas pelas atividades antrópicas (capoeiras) e reduzir a necessidade de expansão da fronteira agrícola.

As áreas de vegetação secundária (capoeira) desempenham um importante papel ecológico em termos de crescimento florestal, recomposição da paisagem, acúmulo de biomassa, benefícios hidrológicos e manutenção da biodiversidade. Estudos desenvolvidos nos últimos anos comprovaram que o manejo da capoeira torna-se viável desde que sejam conhecidas suas potencialidades (Kato et al., 1999; Denich et al., 2002, 2004, 2005). O sistema de corte e trituração da biomassa aérea da vegetação secundária, com a formação de cobertura morta para o solo, e o enriquecimento da capoeira com o plantio de leguminosas arbóreas de crescimento rápido para acelerar o acúmulo da biomassa e nutrientes são alternativas de preparo de área sem o uso do fogo (Kato et al., 1999; Denich et al., 2002). Esse sistema evita perdas de nutrientes, melhora as condições químicas, físicas e biológicas do solo e garante melhor balanço de nutrientes e carbono, pois libera cinco vezes menos gás carbônico $\left(\mathrm{CO}_{2}\right)$ em comparação ao preparo de área com queima (Davidson et al., 2008). Ele também reduz os riscos de incêndios acidentais e cria a possibilidade de períodos consecutivos de cultivos, o que aumenta a intensidade de uso da terra e mantém a produtividade no sistema ao longo do tempo (Kato et al., 1999; Denich et al., 2002).

O material vegetal triturado e distribuído na área (cobertura morta) mantém a umidade do solo por um período maior, o que possibilita a flexibilização do calendário agrícola e o plantio em maio, julho e dezembro (Kato et al., 2003); por isso, torna-se uma alternativa para o produtor rural familiar amenizar os efeitos do período seco na propriedade agrícola. Esse é um fator importante para a região, pois o nordeste paraense apresenta um período de seca, entre setembro e novembro, que compromete o desenvolvimento das culturas agrícolas, por afetar a produção de alimentos e a criação de animais na pequena propriedade.

Entre as principais culturas da agricultura familiar, no estado do Pará, o milho se destaca por suas inúmeras aplicações na propriedade agrícola, principalmente quanto à sua utilização na alimentação humana e animal, e para a geração de receita mediante a comercialização da produção excedente (Cruz et al., 2008). Em sistemas de rotação de culturas, o milho também é indicado para reduzir o potencial do patógeno responsável pela podridão mole das raízes de mandioca, doença que atualmente afeta drasticamente esta cultura na região (Reis \& Forcelini, 1995).

O objetivo deste trabalho foi avaliar o crescimento e a produção de fitomassa de três variedades de milho submetidas a diferentes manejos da capoeira, em sistema de corte e trituração, em Marapanim, nordeste do Pará, no período da seca.

\section{Material e Métodos}

O experimento foi conduzido em campo, na comunidade de São João $\left(1^{\circ} 00^{\prime} 4^{\prime \prime} \mathrm{S}, 47^{\circ} 38^{\prime} 3^{\prime \prime W}\right)$, no Município de Marapanim, área limítrofe com o Município de Igarapé-Açú, Zona Bragantina, nordeste do Estado do Pará. A área experimental, com aproximadamente 0,5 ha, caracteriza-se por um solo Argissolo Amarelo distrófico, com textura que varia de arenosa a média. O clima da região é quente e úmido, do tipo Ami, segundo Köppen, tropical sem ocorrência de inverno estacional, com temperaturas médias anuais em torno de $26^{\circ} \mathrm{C}$, que podem chegar a $31^{\circ} \mathrm{C}$ no período seco. Na região, as estações do ano são associadas à distribuição das chuvas, com ocorrência de maior pluviosidade de março a abril e menor de setembro a novembro.

Em março de 2006, a vegetação secundária de oito anos foi submetida à trituração com implemento fresador florestal e, em seguida, foi realizado o plantio de mandioca (Manihot esculenta cv. Cearense), em espaçamento $1 \times 1 \mathrm{~m}$, sob o material triturado distribuído na área como cobertura morta. Em junho de 2007, quando a área estava coberta pela cultura da mandioca, foi instalado o experimento de enriquecimento de capoeira, em delineamento em blocos ao acaso, com 12 parcelas amostrais de $10 \times 12 \mathrm{~m}$, com três tipos de manejo de capoeira: capoeira natural ou espontânea; capoeira enriquecida com ingá [Inga edulis Mart. (Fabaceae)] e tachi-branco [Sclerolobium paniculatum Vogel (Fabaceae)], leguminosas arbóreas de rápido crescimento já testadas no sistema de corte e trituração 
(Brienza Junior et al., 2000); e capoeira enriquecida com ingá, tachi-branco e com adubação fosfatada.

As espécies leguminosas foram plantadas alternadamente, em espaçamento de $2 \times 2 \mathrm{~m}$, entre linhas de mandioca, e adubadas com fosfato de baixa solubilidade na dosagem de $200 \mathrm{~g}$ por cova $\left(165 \mathrm{~kg} \mathrm{ha}^{-1}\right.$ de $\left.\mathrm{P}_{2} \mathrm{O}_{5}\right)$. Em outubro de 2007, após a colheita da mandioca, realizou-se o coroamento nas leguminosas, e a área experimental entrou em pousio, o que totalizou um período de enriquecimento da capoeira de 23 meses.

Em maio de 2009, foi iniciado o preparo da área para a instalação do experimento com milho, com uma segunda trituração da capoeira, em que o material triturado foi distribuído na área e mantido sobre o solo. $\mathrm{O}$ delineamento em blocos ao acaso foi preservado para a instalação do experimento com milho.

Após 60 dias (início do mês de julho de 2009), três variedades de milho adaptadas à solos ácidos e com baixo nível de fósforo (BRS Sol da Manhã, BRS 4154 Saracura e BR 106) foram plantadas no espaçamento de $1 \times 0,5 \mathrm{~m}$, e as parcelas foram subdivididas em não adubadas e adubadas (NPK), com um total de 18 tratamentos e quatro repetições: três variedades de milho cultivadas em três manejos da capoeira, com dois tipos de adubação complementar (NPK). As parcelas experimentais correspondentes à cada tratamento foram constituídas de 11 fileiras, cada uma com 12 plantas por subparcela, o que corresponde à sua área útil.

As propriedades químicas do solo, na camada de 0-20 cm, indicaram: $\mathrm{pH}$ em $\mathrm{H}_{2} 0$ de 4,8; $10,5 \mathrm{~g} \mathrm{~kg}^{-1} \mathrm{de}$ MO; $0,14 \%$ de $\mathrm{N} ; 2 \mathrm{mg} \mathrm{dm}^{-3}$ de P; $22 \mathrm{mg} \mathrm{dm}^{-3}$ de K ; $12 \mathrm{mg} \mathrm{dm}^{-3} \mathrm{de} \mathrm{Na} ; 0,8 \mathrm{mg} \mathrm{dm}^{-3} \mathrm{de} \mathrm{Ca}_{0} 0,4 \mathrm{cmol}_{\mathrm{c}} \mathrm{dm}^{-3} \mathrm{de}$ $\mathrm{Mg}$; 0,6 $\mathrm{cmol}_{\mathrm{c}} \mathrm{dm}^{-3} \mathrm{de} \mathrm{Al}$; e 6,60 $\mathrm{cmol}_{\mathrm{c}} \mathrm{dm}^{-3} \mathrm{de} \mathrm{H}+\mathrm{Al}$.

A semeadura do milho foi efetuada com semeadoras manuais reguladas para distribuir três a quatro sementes por cova; a cobertura morta foi afastada e as sementes incorporadas de 1 a $2 \mathrm{~cm}$ de profundidade do solo. A cova não foi completamente fechada, para facilitar a germinação do milho. Quinze dias após a semeadura, realizou-se o desbaste, tendo-se deixado duas plântulas por cova. Após cinco dias, realizou-se manualmente uma adubação complementar com NPK 10-28-10 (10 g por cova), na metade das parcelas experimentais, tendo-se aplicado o fertilizante a aproximadamente $10 \mathrm{~cm}$ ao lado de cada cova, com $2 \mathrm{~cm}$ de profundidade, com base na análise de solo realizada.
As avaliações foram realizadas de agosto a novembro, de acordo com o estádio fenológico de cada variedade. Os efeitos dos tratamentos sobre o crescimento e a produção de fitomassa de milho foram avaliados pelas variáveis: altura das plantas (do solo à extremidade da inflorescência masculina), altura diferencial (diferença de altura entre estádios fenológicos diferentes), altura da inserção da primeira espiga (do solo à inserção da espiga mais próxima), diâmetro do colmo (medido aproximadamente a $10 \mathrm{~cm}$ acima do solo), diâmetro diferencial (diferença de diâmetro entre estádios fenológicos diferentes), número de folhas, massa de matéria úmida (MU) e seca (MS) (parte aérea da planta sem as espigas), e estande final (número de plantas por área útil, isto é, área plantada sem considerar as bordas). As variáveis foram avaliadas com base na média de amostragem de oito plantas coletadas na área útil de cada subparcela.

As medições de altura e diâmetro do colmo foram realizadas no início e no final do período que, segundo Cruz et al. (2008), é considerado crítico para o ciclo da cultura: do estádio fenológico $\mathrm{V}_{10}$ (aproximadamente seis semanas após a emergência) ao $\mathrm{R}_{1}$ (de nove a dez semanas após a emergência). As variáveis altura da inserção da primeira espiga, número de folhas, MU e MS, e estande final foram avaliadas na maturação fisiológica (de 110 a 130 dias após o plantio, independentemente da precocidade da variedade). As variedades BRS Sol da Manhã e BRS 4154 Saracura apresentam ciclo precoce, e a BR 106 semiprecoce.

Para a avaliação da MU e da MS, as plantas (sem espigas) foram pesadas e, em seguida, foram coletadas, em sacos de papel, subamostras de cada área útil para a avaliação da MS. As amostras foram secas em estufa a $65^{\circ} \mathrm{C}$, sob ventilação forçada, até atingirem massa constante.

Os dados foram processados com o auxílio do programa Sisvar (Ferreira, 2008). Avaliaramse o crescimento e a produção de MU e MS em diferentes manejos da capoeira, com ou sem adubação complementar (NPK), e as possíveis interações entre estes fatores. Foram realizadas análises de variância, e as médias foram comparadas pelo teste de Tukey, a 5\% de probabilidade.

\section{Resultados e Discussão}

O crescimento e a produção de biomassa da variedade BRS Sol da Manhã não foi influenciada pelo efeito da interação entre o manejo da capoeira 
e a adubação complementar. Entretanto, o tipo de manejo da capoeira influenciou positivamente a altura das plantas no estádio fenológico $\mathrm{R}_{1}$ e a produção de MU e MS, enquanto a aplicação de NPK, realizada durante o cultivo, contribuiu para um incremento na altura em $V_{10}$ e $R_{1}$, na altura da primeira espiga, no diâmetro do colmo em $\mathrm{V}_{10}$ e $\mathrm{R}_{1}$, e na produção de $\mathrm{MU}$ e MS (Tabela 1). Kato et al. (2002, 2003), em estudos de genótipos de milho em sistema de corte e trituração, também obtiveram resultados semelhantes para essa variedade.

$\mathrm{Na}$ variedade BRS 4154 Saracura, observou-se interação significativa entre o manejo da capoeira e a adubação complementar, para as variáveis altura da primeira espiga e diâmetros do colmo em $\mathrm{V}_{10}$ e $\mathrm{R}_{1}$. $\mathrm{O}$ tipo de manejo da capoeira influenciou a altura das plantas em $\mathrm{V}_{10}$ e $\mathrm{R}_{1}$, a altura da primeira espiga, os diâmetros do colmo em $\mathrm{V}_{10}$ e $\mathrm{R}_{1}$, e a produção de $\mathrm{MU}$ e MS (Tabela 1). Kato et al. (2003) também constataram efeito da adubação complementar com NPK sobre essas variáveis, na cultivar BRS 4254 Saracura.

$\mathrm{Na}$ variedade BR 106, observou-se interação significativa entre o manejo da capoeira e a adubação somente para a altura das plantas, nos dois estádios fenológicos avaliados (Tabela 1). O tipo de manejo influenciou a altura da planta, a altura da primeira espiga e a produção de MU e MS; a adubação complementar apresentou efeito significativo sobre estas variáveis e também sobre o diâmetro do colmo em $\mathrm{V}_{10}$ e $\mathrm{R}_{1}$. Kato et al. $(2002,2003)$ observaram resultados semelhantes para a variedade BR 106.

A altura das plantas nos estádios fenológicos $V_{10}$ e $R_{1}$ e a altura da inserção da primeira espiga não apresentaram diferença entre as variedades cultivadas (Tabela 2). No entanto, houve efeito significativo da variedade de milho sobre a variável altura diferencial, entre os estádios fenológicos.

$\mathrm{O}$ enriquecimento da capoeira com as leguminosas arbóreas e com o uso da adubação fosfatada e da adubação complementar com NPK proporcionou o maior valor de altura no estádio $R_{1}$ observado no experimento, na variedade BRS Sol da Manhã (Figura $1 \mathrm{~B}$ ). Na variedade BRS 4154 Saracura, os manejos com capoeira enriquecida com as leguminosas apenas e com capoeira enriquecida + adubação fosfatada, ambos com adubação complementar com NPK, proporcionaram as maiores alturas das plantas nos estádios $\mathrm{V}_{10}$ e $\mathrm{R}_{1}$ (Figuras $1 \mathrm{~A}$ e $1 \mathrm{~B}$ ) e da inserção da primeira espiga. Na variedade BR 106, os manejos influenciaram a altura nos estádios $\mathrm{V}_{10}$ e $\mathrm{R}_{1}$ (Figura $1 \mathrm{~A}$ e $1 \mathrm{~B})$ e a altura da inserção da primeira espiga. Estes resultados estão de acordo com os obtidos por Kato et al. (2003) quanto ao desempenho da cultura do milho e ao tipo de manejo praticado.

A adubação complementar com NPK promoveu o incremento na altura das plantas no estádio fenológico $\mathrm{R}_{1}$ das três variedades analisadas (Figura $1 \mathrm{~B}$ ). $\mathrm{O}$ efeito do manejo com capoeira enriquecida e com capoeira enriquecida + adubação fosfatada, somado à adubação

Tabela 1. Quadrados médios do modelo analítico adotado na análise de variância para os efeito do manejo da capoeira (M) e da adubação complementar com NPK (A) sobre as variáveis de crescimento e de produção de matéria úmida (MU) e seca (MS) de três variedades de milho.

\begin{tabular}{|c|c|c|c|c|c|c|c|c|c|c|c|c|}
\hline \multirow[t]{2}{*}{ Variáveis } & \multicolumn{4}{|c|}{ BRS Sol da Manhã } & \multicolumn{4}{|c|}{ BRS 4154 Saracura } & \multicolumn{4}{|c|}{ BR 106} \\
\hline & $\mathrm{M}$ & $\mathrm{A}$ & $(\mathrm{MxA})$ & $\overline{\text { QMR }}$ & $\mathrm{M}$ & $\mathrm{A}$ & $(\mathrm{MxA})$ & QMR & $\mathrm{M}$ & $\mathrm{A}$ & $(\mathrm{MxA})$ & QMR \\
\hline$\overline{\text { Altura } 1\left(\mathrm{~V}_{10}\right)}$ & $0,172^{\mathrm{ns}}$ & $0,98 * *$ & $0,008^{\mathrm{ns}}$ & 0,08 & $0,295 * *$ & $1,576^{* *}$ & $0,098^{\mathrm{ns}}$ & 0,03 & $0,711 * *$ & $0,833 * *$ & $0,146^{* *}$ & 0,01 \\
\hline Altura $2\left(\mathrm{R}_{1}\right)$ & $0,249 *$ & $1,067 * *$ & $0,001^{\mathrm{ns}}$ & 0,06 & $0,311 * *$ & $1,279 * *$ & $0,037^{\mathrm{ns}}$ & 0,02 & $0,261 * *$ & $1,101 * *$ & $0,139 * *$ & 0,02 \\
\hline Altura diferencial (2-1) & $0,002^{\mathrm{ns}}$ & $0,011^{\mathrm{ns}}$ & $0,014^{\mathrm{ns}}$ & 0,01 & $0,018^{\mathrm{ns}}$ & $0,255^{* *}$ & $0,076^{\mathrm{ns}}$ & 0,03 & $0,761 * *$ & $0,004^{\mathrm{ns}}$ & $0,004^{\mathrm{ns}}$ & 0,01 \\
\hline Altura da primeira espiga & $0,114^{\mathrm{ns}}$ & $0,308 * *$ & $0,009^{\mathrm{ns}}$ & 0,03 & $0,095 * *$ & $0,4 * *$ & $0,155 * *$ & 0,02 & $0,159 * *$ & $0,277 * *$ & $0,023^{\mathrm{ns}}$ & 0,03 \\
\hline Diâmetro $1\left(\mathrm{~V}_{10}\right)$ & $15,56^{\mathrm{ns}}$ & $86,64 * *$ & $1,74^{\mathrm{ns}}$ & 5,33 & $38,22 * *$ & $108,16^{* *}$ & $7,67 * *$ & 1,25 & $4.548^{\mathrm{ns}}$ & $98,58 * *$ & $0,01^{\mathrm{ns}}$ & 4,74 \\
\hline Diâmetro $2\left(\mathrm{R}_{1}\right)$ & $20,97^{\mathrm{ns}}$ & $106,77 * *$ & $1,94^{\mathrm{ns}}$ & 6,75 & $53,49 * *$ & $109,4 * *$ & $12,59 *$ & 3,08 & $6.465^{\mathrm{ns}}$ & $116,95 * *$ & $0,85^{\mathrm{ns}}$ & 4,92 \\
\hline Diâmetro diferencial (2-1) & $0,0001^{\mathrm{ns}}$ & $0,0001^{\mathrm{ns}}$ & $0,002^{\mathrm{ns}}$ & 0,01 & $0,001^{\mathrm{ns}}$ & $0,016^{\mathrm{ns}}$ & $0,003^{\mathrm{ns}}$ & 0,01 & $0^{\text {ns }}$ & $0,006^{\mathrm{ns}}$ & $0,005^{\mathrm{ns}}$ & 0,01 \\
\hline Número de folhas & $1,625^{\mathrm{ns}}$ & $8,167^{\mathrm{ns}}$ & $0,542^{\mathrm{ns}}$ & 2,08 & $4,625^{\mathrm{ns}}$ & $6^{\mathrm{ns}}$ & $1,125^{\mathrm{ns}}$ & 2,14 & $0,375^{\mathrm{ns}}$ & $7,042^{\mathrm{ns}}$ & $0,292^{\mathrm{ns}}$ & 1,74 \\
\hline Massa total (MU) & $2.300 *$ & $9.600 * *$ & $231^{\mathrm{ns}}$ & 495,00 & $3210 *$ & $4.880^{*}$ & $796^{\mathrm{ns}}$ & 627,00 & $6.280 * *$ & $16.500 * *$ & $856^{\mathrm{ns}}$ & 526,00 \\
\hline Subamostra (MU) & $5.020 * *$ & $10.300 * *$ & $236^{\mathrm{ns}}$ & 599,00 & $2450 * *$ & $3.500 * *$ & $429^{\mathrm{ns}}$ & 403,00 & $3.840 * *$ & $7.290 * *$ & $1.290^{\mathrm{ns}}$ & 495,00 \\
\hline Subamostra (MS) & $2.230 * *$ & $8.420 * *$ & $260^{\mathrm{ns}}$ & 309,00 & $1330 * *$ & $5.170 * *$ & $372^{\mathrm{ns}}$ & 210,00 & $1.770^{*}$ & $5.540 * *$ & $743^{\mathrm{ns}}$ & 311,00 \\
\hline
\end{tabular}

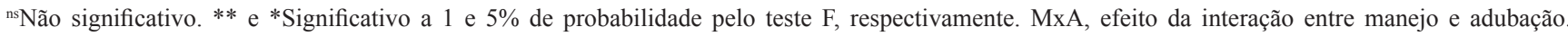
QMR, quadrado médio do resíduo. 
complementar com NPK, proporcionou os melhores resultados, e possibilitou que as plantas atingissem alturas entre 1,50 e $1,58 \mathrm{~m}$ e altura da inserção da primeira espiga entre 0,80 e $0,87 \mathrm{~m}$. Kato et al. (2002, 2003) observaram maiores alturas de plantas e de inserção da primeira espiga de milho em condições semelhantes de cultivo no sistema de corte e trituração, com adubação complementar. Os autores obtiveram plantas de milho com altura média de $1,59 \mathrm{~m}$ e altura da inserção da primeira espiga de aproximadamente 0,84 m. Estes resultados evidenciam a resposta da cultura do milho ao tipo de manejo da capoeira e da adubação praticados, pois a cobertura morta distribuída sobre o solo desempenha um papel fundamental na ciclagem de nutrientes, tanto os adicionados por meio de fertilizantes minerais quanto os provenientes da matéria orgânica do solo (Torres et al., 2008; Silva et al., 2009).

O diâmetro do colmo nos estádios fenológicos $V_{10}$ e $R_{1}$ e a taxa de crescimento entre estes estádios (diâmetro diferencial) não sofreram efeito das variedades estudadas (Tabela 2). Nas variedades BRS Sol da Manhã e BR 106, foram observados efeitos significativos da adubação complementar com NPK nos diâmetros $\mathrm{V}_{10}$ e $\mathrm{R}_{1}$ (Figuras $1 \mathrm{C}$ e $1 \mathrm{D})$. Os diâmetros do colmo na variedade BRS 4154 Saracura foram influenciados pelo manejo da capoeira e pela adubação complementar, tendo apresentado maiores valores nos manejos com capoeira enriquecida e capoeira enriquecida + adubação fosfatada, ambos

Tabela 2. Quadrados médios do modelo analítico adotado na análise de variância para os efeitos das variedades de milho sobre as variáveis de crescimento e de produção de matéria úmida (MU) e seca (MS).

\begin{tabular}{lcc}
\hline Variáveis & Variedade & QMR \\
\hline Altura 1 $\left(\mathrm{V}_{10}\right)$ & $0,37^{\mathrm{ns}}$ & 0,12 \\
Altura 2 $\left(\mathrm{R}_{1}\right)$ & $0,14^{\mathrm{ns}}$ & 0,11 \\
Altura diferencial $(2-1)$ & $0,32^{* *}$ & 0,04 \\
Altura da primeira espiga & $0,03^{\mathrm{ns}}$ & 0,05 \\
Diâmetro 1 $\left(\mathrm{V}_{10}\right)$ & $4,48^{\mathrm{ns}}$ & 9,17 \\
Diâmetro 2 $\left(\mathrm{R}_{1}\right)$ & $12,53^{\mathrm{ns}}$ & 11,47 \\
Diâmetro diferencial $(2-1)$ & $0,02^{\mathrm{ns}}$ & 0,01 \\
Número de folhas & $27,13^{* *}$ & 2,11 \\
Massa total $(\mathrm{MU})$ & $5.464,93^{*}$ & $1.274,79$ \\
Subamostra $(\mathrm{MU})$ & $5.191,51^{*}$ & $1.081,33$ \\
Subamostra $(\mathrm{MS})$ & $1.476,17^{\mathrm{ns}}$ & 688,16 \\
\hline
\end{tabular}

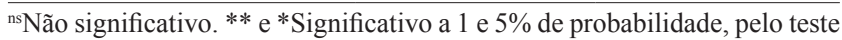
$\mathrm{F}$, respectivamente. QMR, quadrado médio do resíduo. com adubação complementar (Figura $1 \mathrm{C}$ e $1 \mathrm{D}$ ). Fernandes et al. (2005), ao avaliar respostas de milho a diferentes doses de adubação, não identificaram diferenças no diâmetro do colmo das variedades, que alcançaram valores entre 18,02 e 19,81 mm. Demétrio et al. (2008), ao comparar o desempenho de espécies de milho submetidos a diferentes espaçamentos e densidades populacionais, observaram que, quanto maior a densidade, menor o diâmetro do colmo. Para Gross et al. (2006), isso é resultado de um decréscimo de massa de matéria seca individual, em virtude da competição pelos recursos do meio.

A variedade BR 106 foi a que desenvolveu maior número de folhas por planta, o que evidencia o efeito da variedade de milho sobre essa variável (Tabela 2). Embora as variedades tenham se desenvolvido de forma equilibrada e sem sofrer influência do manejo da capoeira ou da adubação quanto a essa variável (Tabela 1), esse comportamento era esperado em razão da variedade BR 106 ser de ciclo semiprecoce, que necessita atingir um porte mais elevado em comparação às outras variedades precoces avaliadas, para expressar seu rendimento máximo (Cruz et al., 2008). Cultivares precoces geralmente possuem plantas de menor altura, menor massa vegetativa e menor tamanho das folhas. Estas características morfológicas determinam um menor sombreamento na cultura, o que possibilita menor espaçamento entre as plantas e melhor aproveitamento de luz para os processos fotossintéticos. Quando outros fatores ambientais são favoráveis, a interceptação da radiação solar pelo dossel exerce grande influência sobre o desenvolvimento da cultura do milho (Pereira Filho \& Cruz, 2003).

A variedade BR 106 apresentou maior MU entre as variedades estudadas; entretanto, este desempenho não foi observado em relação a MS (Figuras 2 A, 2 B e 2 C). Conforme Borghi et al. (2004), a maior MU por área nem sempre corresponde a uma maior MS. Para a variedade BRS Sol da Manhã, o manejo com capoeira enriquecida + adubação fosfatada e complementar promoveu a maior MU e MS (Figura $2 \mathrm{~B}$ e $2 \mathrm{C}$ ). Fernandes et al. (2005), em avaliações de milho com diferentes adubações, também obtiveram resultados significativos da fertilização, com a variedade BRS Sol da Manhã, que apresentou o melhor desempenho em produção de MS.

A BRS 4154 Saracura apresentou os maiores valores de MU e MS nos manejos com capoeira enriquecida 
$(104,63$ e $71,03 \mathrm{~g}$, respectivamente) e capoeira enriquecida + adubação fosfatada (104,45 e 72,38 g, respectivamente), ambos com adubação complementar. Os manejos proporcionaram à variedade BR 106 os maiores valores de MU, que atingiram 154,80 e 142,63 g
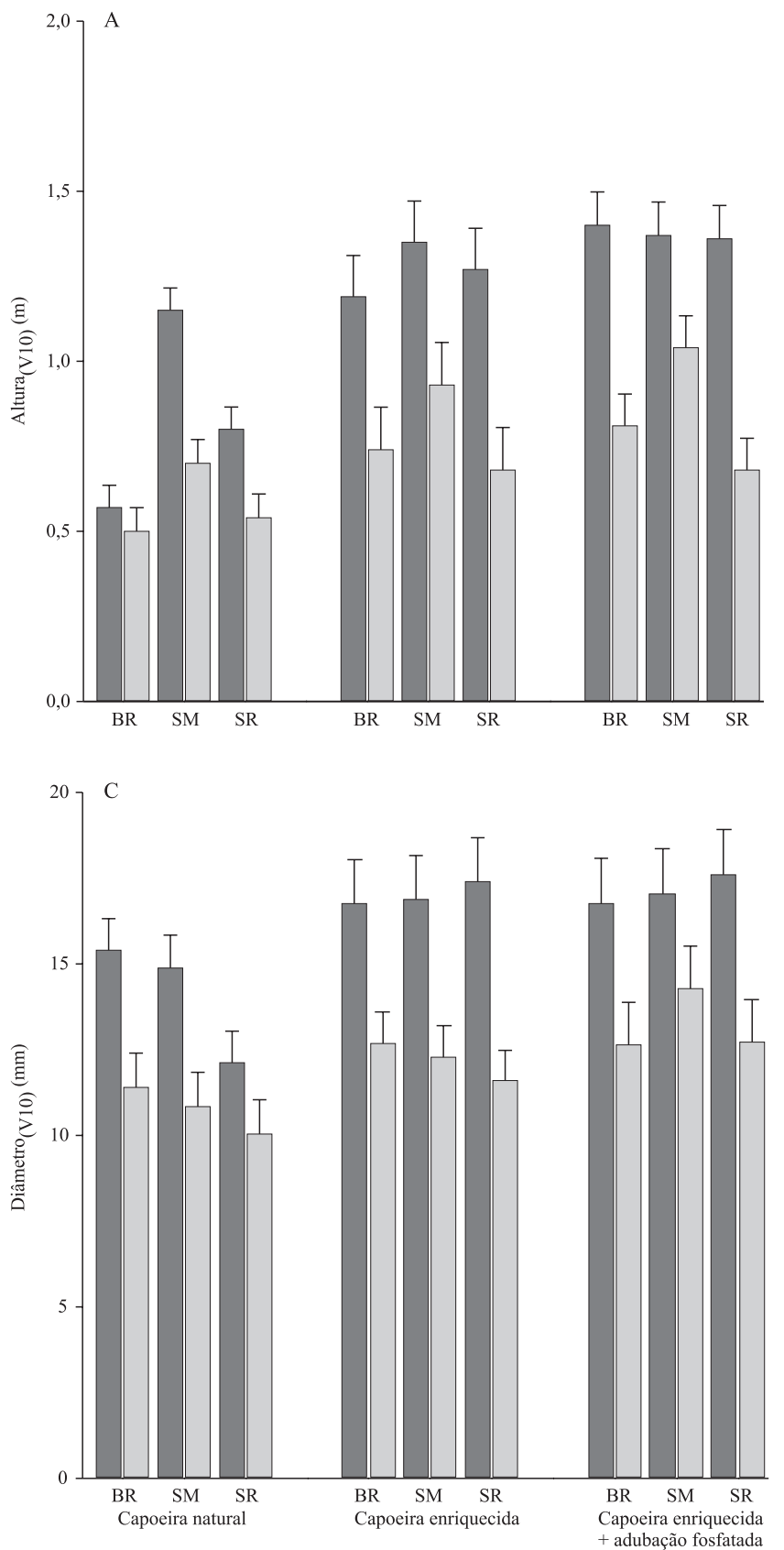

nos manejos com capoeira enriquecida e capoeira enriquecida + adubação fosfatada, respectivamente, ambos com adubação complementar. Estes resultados são opostos aos encontrados por Fernandes et al. (2005), que constataram que o desempenho da
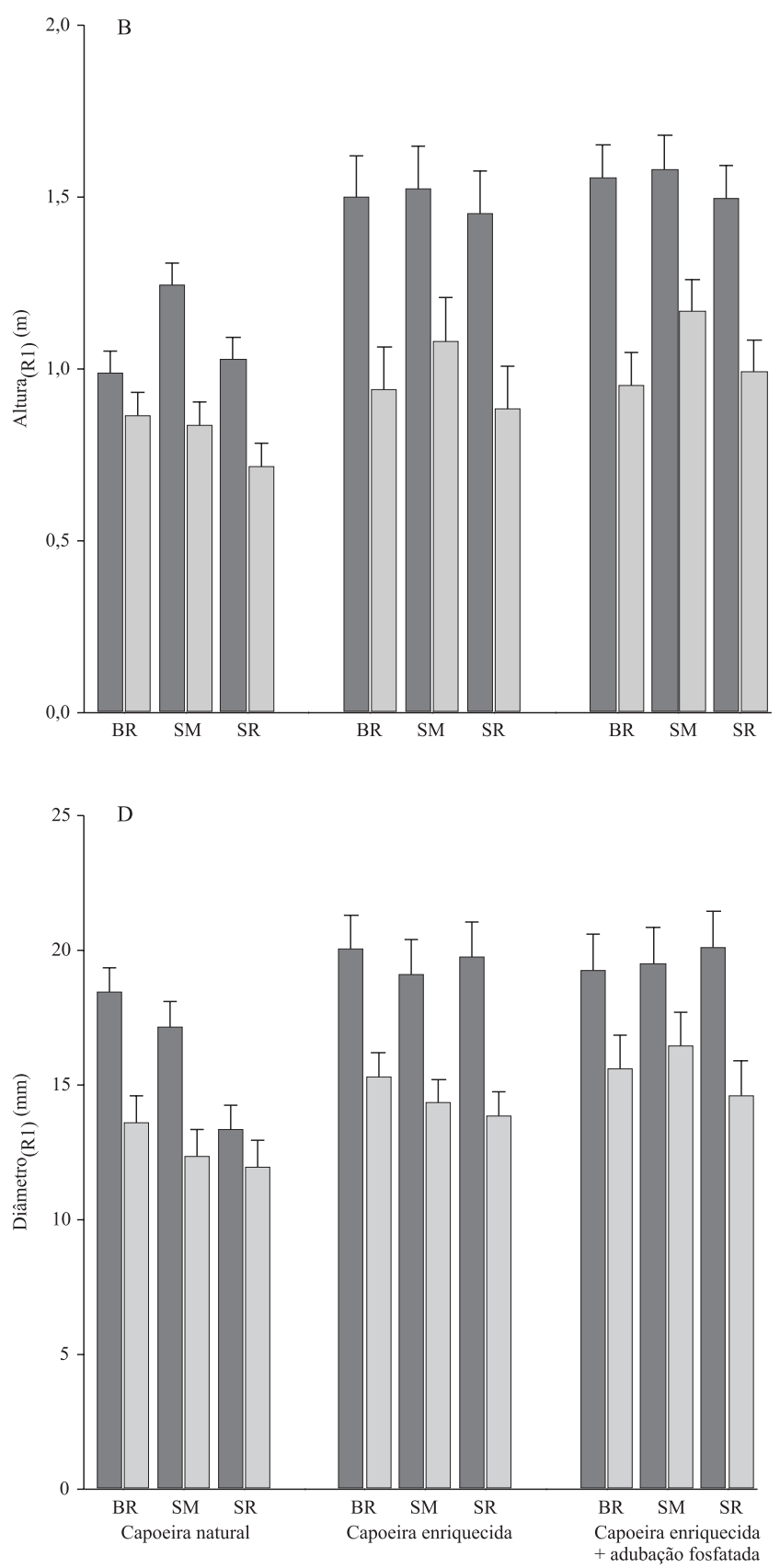

Figura 1. Efeito do manejo da capoeira e da adubação complementar (NPK) na altura da planta (A e B) e no diâmetro do colmo (C e D) das variedades de milho BR 106 (BR), BRS Sol da Manhã (SM) e BRS 4154 Saracura (SR), nos estádios V 10 e $R_{1}$, cultivadas em manejos com capoeira natural, capoeira enriquecida com leguminosas arbóreas e capoeira enriquecida com leguminosas arbóreas e adubação fosfatada. 
variedade BR 106 não foi superior aos valores obtidos com a variedade BRS Sol da Manhã. O aumento na MS da parte aérea das plantas de milho é uma resposta ao incremento das doses de fósforo, como foi observado por Harger et al. (2007) ao avaliar o
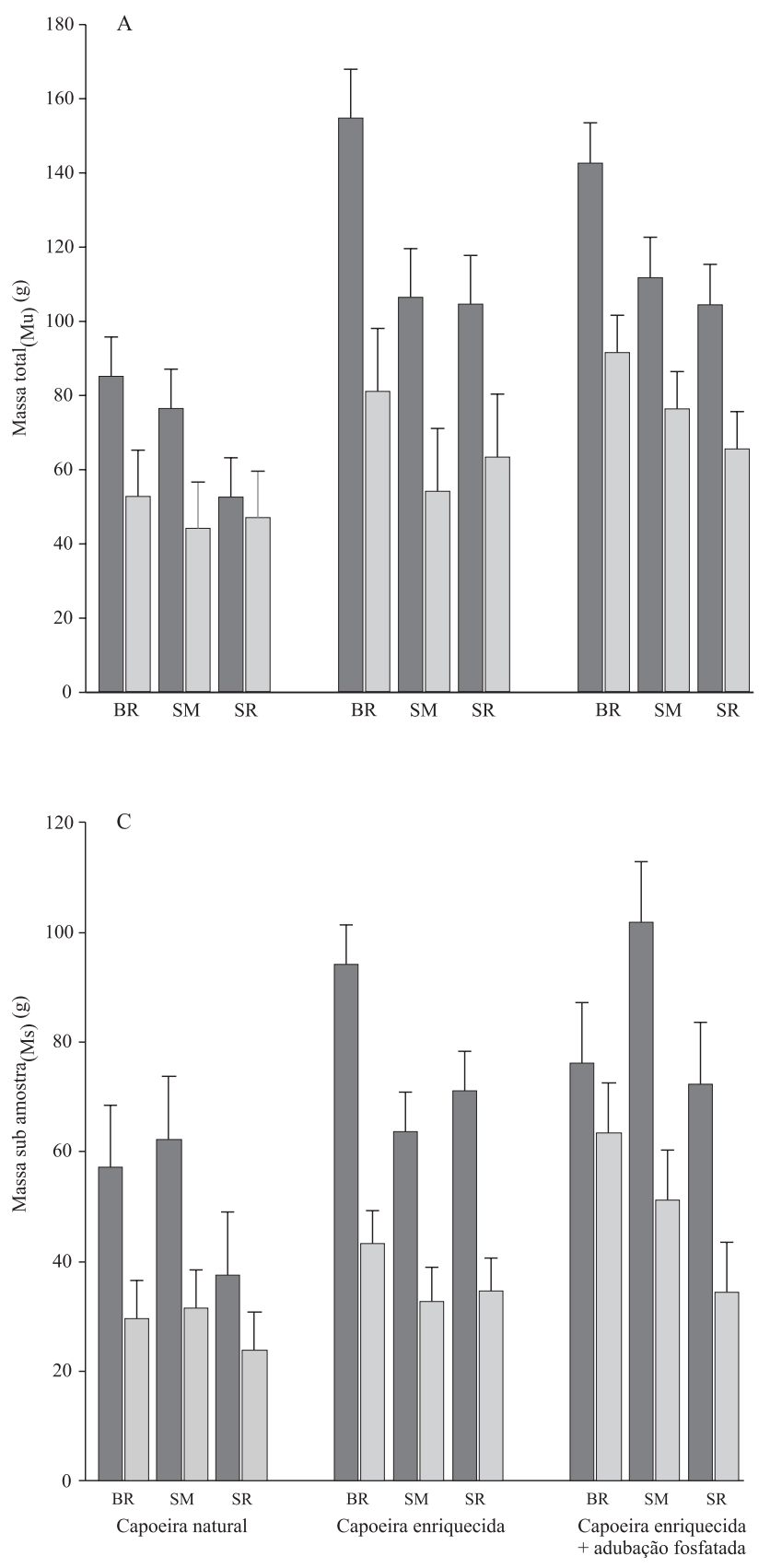

crescimento da cultura quanto à este nutriente. Silva et al. (2009) observaram que o fósforo aumenta a assimilação de nitrogênio proveniente da adubação, o que contribui para um ambiente agrícola favorável ao desenvolvimento da cultura.
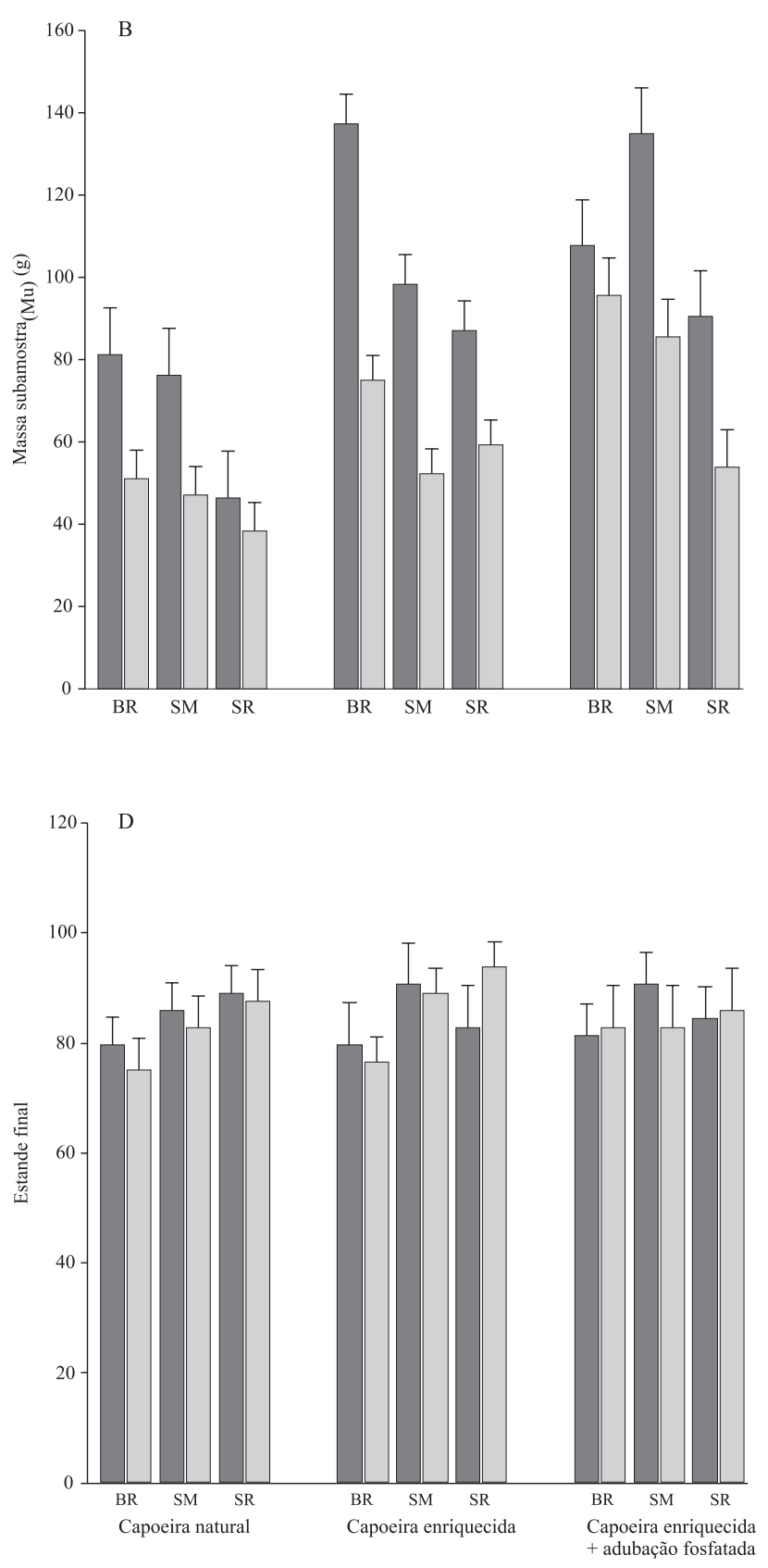

Adubação complementar com NPK (+)

$\square$ Adubação complementar com NPK (-)

Figura 2. Efeito do manejo da capoeira e da adubação complementar (NPK) na produção de matéria úmida (MU) (A e B) e seca (MS) (C) e no estande final (D) das variedades de milho BR 106 (BR), BRS Sol da Manhã (SM) e BRS 4154 Saracura (SR), nos estádios $\mathrm{V}_{10}$ e $\mathrm{R}_{1}$, cultivadas em manejos com capoeira natural, capoeira enriquecida com leguminosas arbóreas e capoeira enriquecida com leguminosas arbóreas e adubação fosfatada. 
As variedades diferiram quanto ao estande final (Tabela 2), sendo que BRS Sol da Manhã e BRS 4154 Saracura apresentaram maiores estandes finais em relação à BR 106. Contudo, não foram detectadas diferenças em relação ao manejo da capoeira e da adubação (Figura 2 D) nem das interações entre esses manejos (Tabela 1). O milho, ao contrário de outras gramíneas, não perfilha para compensar possíveis falhas de semeadura. Dessa forma, de acordo com Pereira Filho \& Cruz (2003), o estande tem papel fundamental para o rendimento da cultura, uma vez que pequenas variações na densidade têm grande influência no rendimento final.

\section{Conclusões}

1. O manejo com capoeira enriquecida e capoeira enriquecida + adubação fosfatada influencia positivamente a altura das plantas, o diâmetro do colmo e a produção de massa de matéria úmida e seca.

2. A adubação complementar com NPK durante o cultivo do milho potencializa o efeito dos manejos da capoeira em relação à altura das plantas, ao diâmetro do colmo e à produção de matéria úmida e seca.

3. As variedades BRS Sol da Manhã, BRS 4154 Saracura e BR 106 cultivadas em manejo com capoeira enriquecida, adubação fosfatada e adubação complementar (NPK) são alternativas viáveis para a cultura do milho no período seco, no nordeste paraense.

\section{Agradecimentos}

À Embrapa Amazônia Oriental e à Universidade Federal Rural daAmazônia, pelas instalações e materiais para o desenvolvimento do experimento; à Embrapa Milho e Sorgo, pelo fornecimento das sementes de milho; e ao Conselho Nacional de Desenvolvimento Científico e Tecnológico, pelo apoio financeiro aos projetos de pesquisa.

\section{Referências}

BORGHI, É.; MELLO, L.M.M. de; CRUSCIOL, C.A.C. Adubação por área e por planta, densidade populacional e desenvolvimento do milho em função do sistema de manejo do solo. Acta Scientiarum. Agronomy, v.26, p.337-345, 2004.

BRIENZA JUNIOR, S.; COSTA, V. de O.; SANTOS, W.E.S.; PANTOJA, R. de F.R.; SÁ, T.D. de A.; VIELHAVER, K.; DENICH, M.; VLEK, P.L.G.V. Enriquecimento de capoeira com árvores leguminosas contribuindo para o acúmulo de biomassa na agricultura familiar do nordeste do Pará, Brasil. In: SEMINÁRIO SOBRE MANEJO DA VEGETAÇÃO SECUNDÁRIA PARA A SUSTENTABILIDADE DA AGRICULTURA FAMILIAR DA AMAZÔNIA ORIENTAL, 2000, Belém. Anais. Belém: Embrapa Amazônia Oriental: CNPq, 2000. p.83-84. (Embrapa Amazônia Oriental. Documentos, 69).

CRUZ, J.C.; KARAM, D.; MONTEIRO, M.A.R.; MAGALHÃES, P.C. (Ed.). A cultura do milho. Sete Lagoas: Embrapa Milho e Sorgo, 2008. 517p.

DAVIDSON, E.A.; SÁ, T.D. de A.; CARVALHO, C.J.R.; FIGUEIREDO, R. de O.; KATO, M. do S.A.; KATO, O.R.; ISHIDA, F.Y. An integrated greenhouse gas assessment of an alternative to slash-and-burn agriculture in eastern Amazonia. Global Change Biology, v.14, p.998-1007, 2008.

DEMÉTRIO, C.S.; FORNASIERI FILHO, D.; CAZETTA, J.O.; CAZETTA, D.A. Desempenho de híbridos de milho submetidos a diferentes espaçamentos e densidades populacionais. Pesquisa Agropecuária Brasileira, v.43, p.1691-1697, 2008.

DENICH, M.; VIELHAUER, K.; HEDDEN-DUNKHORST, B. New technologies to replace slash and burn in the eastern Amazon. Zef News, n.9, p.8, 2002.

DENICH, M.; VIELHAUER, K.; KATO, M. do S.A.; BLOCK, A.; KATO, O.R.; SÁ, T.D. de A.; LÜCKE, W.; VLEK, E.P.L.G. Mechanized land preparation in forest-based fallow systems: The experience from Eastern Amazonia. Agroforestry Systems, v.61-62, p.91-106, 2004.

DENICH, M.; VLEK, P.L.G.; SÁ, T.D. de A.; VIELHAUER, K.; LUCKE, W. A concept for the development of fire-free fallow management in the Eastern Amazon, Brazil. Agriculture, ecosystems and environment, v.110, p.43-58, 2005.

FERNANDES, F.C.S.; BUZETTI, S.; ARF, O.; ANDRADE, J.A.C. Doses, eficiência e uso de nitrogênio por seis cultivares de milho. Revista Brasileira de Milho e Sorgo, v.4, p.195-204, 2005.

FERREIRA, D.F. SISVAR: um programa para análises e ensino de estatística. Revista Symposium, v.6, p.36-41, 2008.

GROSS, M.R.; PINHO, R.G.; BRITO, A.H. Adubação nitrogenada, densidade de semeadura e espaçamento entre fileiras na cultura do milho em sistema de plantio direto. Ciência e Agrotecnologia, v.30, p.387-393, 2006.

HARGER, N.; BRITO, O.R.; RALISCH, R.; ORTIZ, F.R.; WATANABE, T.S. Avaliação de fontes e doses de fósforo no crescimento inicial do milho. Semina: Ciências Agrárias, v.28, p.39-44, 2007.

KATO, M. do S.A.; KATO, O.R.; DENICH, M.; VLEK, P.L.G. Fire-free alternatives to slash-and-burn for shifting cultivation in the eastern Amazon region: the role of fertilizers. Field Crops Research, v.62, p.225-237, 1999.

KATO, M. do S.A; KATO, O.R.; JESUS, C.C. de; RENDEIRO, A.C.L. Genótipos de milho para plantio em sistemas de corte e trituração. Belém: Embrapa Amazônia Oriental, 2002. 3p. (Embrapa Amazônia Oriental. Comunicado técnico, 65).

KATO, O.R.; KATO, M. do S.A.; VIELHAUER, K.; BLOCK, A.; JESUS, C.C. Cultivo do milho em sistemas de corte e 
trituração da capoeira na região nordeste do Pará - efeito da época do preparo de área. Belém: Embrapa Amazônia Oriental, 2003. 18p. (Embrapa Amazônia Oriental. Boletim de pesquisa e desenvolvimento, 19).

PEREIRA FILHO, I.A.; CRUZ, J.C. Colheita, transporte e comercialização do milho-verde. In: PEREIRA FILHO, I.A. (Ed.). O Cultivo do milho-verde. Brasília: Embrapa Informação Tecnológica, 2003. p.183-194.

REIS, E.M.; FORCELINI, C.A. Controle cultural. In: BERGAMIN FILHO, A.; KIMATI, H.; AMORIN, L. (Ed). Manual de fitopatologia. 3.ed. São Paulo: Agronômica Ceres, 1995. v.1, p.710-716.
SILVA, P.C.G.; FOLONI, J.S.S.; FABRIS, L.B.; TIRITAN, C.S. Aproveitamento de nitrogênio pelo milho, em razão da adubação verde, nitrogenada e fosfatada. Pesquisa Agropecuária Brasileira, v.44, p.118-127, 2009.

TORRES, J.L.R.; PEREIRA, M.G.; FABIAN, A.J. Produção de fitomassa por plantas de cobertura e mineralização de seus resíduos em plantio direto. Pesquisa Agropecuária Brasileira, v.3, p.421-428, 2008.

WATRIN, O. dos S.; GERHARD, P.; MACIEL, M. de N.M. Dinâmica do uso da terra e configuração da paisagem em antigas áreas de colonização de base econômica familiar, no Nordeste do Estado do Pará. Geografia, v.34, p.455-472, 2009.

Recebido em 23 de julho de 2010 e aprovado em 21 de janeiro de 2011 